\title{
Tools for building environmental culture in Russian companies
}

\author{
Olga Rasskazova $^{1, *}$, Igor Alexandrov $^{1}$, Andrey Burmistrov ${ }^{1}$, and Maria Siniavina ${ }^{1}$ \\ ${ }^{1}$ Peter the Great St.Petersburg Polytechnic University (SPbPU), 29, Polytechnicheskaya, 195251 St. \\ Petersburg, Russia
}

\begin{abstract}
Environmentally responsible behavior of modern companies allows them to reduce the negative impact on the environment, as well as contributes to its competitiveness, sustainable development, formation of internal and external positive image. In this paper, we looked into the key concepts of environmental management of personnel, in particular, environmental thinking, environmental behavior, environmental culture, and reflected on interconnection of these concepts. We have offered tools for developing an environmental culture among the staff of a Russian company, which will enable them to achieve their environmental goals, as well as to use economic thinking and behavior in the daily life of their employees. The environmental culture allows people to form a respectful attitude towards nature as a prerequisite for their survival, awareness of the priority of global environmental interests and, at the same time, personal responsibility of each individual.
\end{abstract}

\section{Introduction}

At present, society is beginning to realise the importance of changes in the existing way of interaction with the environment, which will inevitably lead our planet to an environmental disaster. The basic percept envisages development of environmental awareness in public. This can be achieved through transforming peoples' spiritual values, ethical principles, legislation, social constructs, and contriving new needs and strategies of their satisfaction. For this purpose, it is necessary to nurture an ecological culture in people. It presupposes changes of life style when the society transforms the system of spiritual values, ethical principles, legal norms and social institutions, forms new needs and ways of their realization. According to research conducted by Greenpeace the solution of global problems requires the unity of international efforts, coordinated actions of many states [1]. No country in the world, even the most developed and wealthiest, is able to prevent the global environmental consequences of human activity on its own. An important part of environmental culture is the awareness of the priority of global environmental interests. And at the same time a personal responsibility of an individual for preservation of environment is of paramount importance.

\footnotetext{
*olanka777@yandex.ru
} 


\section{Materials and Methods}

The paper considers data obtained from scientific publications and periodicals, which testify to the state of environmental responsibility of Russian companies. Common misconception of corporations is that the introduction of the environment friendly practices will only lead to an increase in costs. According to the report of the World Wildlife Fund (WWF), 29 out of 60 companies are convinced that their costs will increase; as such they consider it inexpedient to pursue an environmental policy [2]. Although the global experience shows that the implementation of environmental protection measures allows companies to increase its competitive edge and create a positive public image. The best practices of Russian and foreign companies in cultivating environmental awareness in their employees are reviewed. Employees' awareness of personal responsibility for the protection of environment and application of this principle in their daily work allows them to demonstrate their civic position, to unite the team, and is the important element of the overall corporate culture.

\section{Results}

Nowadays, the natural resources on our planet are becoming more scares hence more expensive. The company's corporate social responsibility consists of the following components: economic, social and environmental. The role of environmental responsibility cannot be artificially separated from other Corporate Social Responsibility. All elements are important in the company's sustainable development concept and a balance between them is required. That is, if an organization considers itself a socially responsible, it should pay competitive salaries to its employees; deal with the social issues, and at the same time engage into work to solve problems of environmental pollution. In the age of a rapid technological development, companies can and should pay special attention to environmental responsibility, analyze and optimize their environmental footprint, and effectively use technology to preserve the environment.

One of the obstacles to the development of environmental responsibility in Russia is the lack of information on the part of both state regulators and companies. In many companies, annual statistical information with many indicators of their activities, including environmental ones, is classified. This is becoming a problem for making objective and complete environmental ratings and, moreover, for forming objective public assessments. If a company wants to create a positive environmental image, it is important for it to provide honest information to its customers, suppliers, employees, the population of the region and public organizations dealing with environmental issues. Since few companies in Russia today publish reports on their environmental policies, it is impossible to assess their contribution and see the benefits of implementing environmental standards in their operations. The environmental situation can be changed if a dialogue between stakeholders is established and the efforts of the government, business, society, public organizations and the media are united.

The role of the environmental component is highly dependent on the nature of the company. If the impact on the environment is high, the importance of activities aimed at reducing such impact increases. For example, Russian companies are divided into two types due to their environmentally responsible activities and economic objectives. Companies that ignore environmental issues and objectives are not addressed in this typology. The first type is the companies that are mandated by law to implement environment friendly policies and apply environment protection technologies (groups I and II). The second type is the companies that voluntarily elect to execute the environment friendly policies (groups III and IV 
are included) [3]. Let's consider their specific traits in more detail.

For Group I companies, environmental protection is a compulsory, statutory obligation. These include, as a rule, enterprises extracting and processing natural resources (oil and gas industry, power generating industry, etc.). These companies operate under relatively severe institutional constraints due to strict environmental standards and laws. The main objective of their environment protection activities is to comply with the requirements set out by the legislation and industrial standards.

Group II companies' performance depends on ensuring the environmental characteristics of the managed facility, and they consider natural resources as the object of management. Companies build their business on the basis of the use of these resources; they are interested in its long-term productivity (agriculture, recreational forestry, etc.). This naturally implies that their environmental, ecologically activities are safe.

Group III companies carry out environmental protection activities in order to achieve high economic results. It is especially important for them to ensure their long-term competitiveness in the market. This leads to the need for companies to implement a social responsibility strategy in general, and a voluntary choice of environmental responsibility strategy in particular. Since the implementation of environmental protection measures always involves costs, the management of these companies pays special attention to the consideration of cost factors. Their important goal is to minimize costs (expenses) when making decisions on environmental protection measures. The latter may consist of the following categories [3]:

- Costs of ensuring social and environmental responsibility (implementation of relevant programs, activities);

- Costs caused by the discovery of violations of the principles of social and environmental responsibility (payment of compensation, fines);

- Alternative costs (expenses) caused by a low level of confidence in the company's activities caused by its insufficient attention to environmental issues or violation of the principles of social and environmental responsibility (lost profit, lost marginal income).

Group IV companies oversee environmental activities in the form of corporate philanthropy. They consistently adhere to the idea of social and environmental responsibility, in addition to traditional goals of growth, development and profit. They are more inclined to implement the idea of institutional efficiency than companies belonging to Groups II and III, where the fulfillment of environmental obligations has a strong impact on their economic performance.

This classification should not be considered "hard", as companies in Groups I and IV may have certain economic interests in environmental performance. And, some Group II entities may neglect the conditions of care for the managed ecosystem without thinking about the future of their companies, complying only with formal legal requirements, paying fines, moving to Group I, or going beyond the boundaries of this typology [3].

It is necessary to eliminate misunderstandings by companies about their contribution to solving environmental problems in terms of costs only, deciding that it is more advantageous to pay a fine to environmental regulators than to invest in the installation of expensive cleaning equipment. It is important that companies' management perceive environmentally responsible behavior as an important factor in business development and competitive- 
ness. Companies need to understand that by doing so, they are building a positive internal and external image.

Already today, there is a tendency for customers to find it more enjoyable to deal with companies that are concerned about the environment and not just about increasing profits when choosing a product or service. It is important for them to understand that the company's activities are aimed not only at producing products, but also at preserving the environment and producing environmentally friendly products. Environmentally responsible customers understand that the attitude and actions of companies towards nature will have an impact not only on the quality of their lives, but will also be inherited by their descendants [4].

Advanced eco-focused companies are beginning to think about constructive cooperation by choosing their business partners. For example, when choosing the paper to be used by the staff in the workflow, the companies are beginning to prefer manufacturers who sell certified paper with the FSC (Forest Stewardship Council) mark, confirming their cooperation with environmentally responsible paper manufacturers. It is not uncommon for companies to refuse to cooperate with companies whose main activities cause serious damage to the environment. In 2003, some of the largest international banks adopted "equator principles" that take into account environmental aspects when giving loans to businesses and this project is gradually beginning to be introduced into the policy of Russian banks.

Companies, guided by representatives of the external environment, should prepare such tools of visual agitation as brochures and booklets. Brochures and booklets should contain information about the company's environmental policy and the requirements for environmental behavior of employees and suppliers. The organization's image is positively influenced by the preparation and publication of annual environmental reports. Such reports should be made publicly available so that everyone can read them. Therefore, they should be posted on the Internet, on the company's website, and information from the report can be disseminated through the media (local newspapers, magazines, television, radio, etc.). Thus, corporate environmental responsibility of a company is not just a wish, but a requirement of time, which helps it to be more competitive in the market.

Specialists of the Skolkovo Innovation Center have defined the universal competencies required today and in the near future for employees from different sectors of the economy [5]. Employees, developing and using them, will be able to become more successful and adapt to the requirements of the dynamically changing labor market and be competitive. Such universal skills and abilities also included environmental thinking of employees. It was noted that modern employees need to develop skills of environmentally responsible behavior, understand that natural resources are limited, and everyone is responsible for their rational use.

Let's consider the basic concepts directly related to environmental management of personnel, such as environmental culture, environmental thinking and environmental behavior of a person in order to better understand their essence as they are connected with each other. Environmental culture is the ability of people to use their ecological knowledge and skills in practice. Ecological culture has two important components - ecological thinking (consciousness) and ecological behavior of a person. It is important that people not only possess the necessary knowledge, but also use it in everyday life and work. Environmental thinking is understood as a set of environmental and nature protection ideas, outlook and attitude to nature, strategies of practical activities aimed at natural objects. Environmental behavior - a set of specific actions and actions of people related to the impact on the natural environment, with the use of natural resources.

Environmental culture is organically connected with the essence of the individual as a 
whole, with its different sides and qualities. Interaction of different types of cultures generates an environmental culture, they include:

- Philosophical culture, which enables people to understand and understand the purpose of man as a product of nature and society;

- Political (economic) culture, which allows to provide ecological balance between economic activity of people and the state of nature;

- Legal culture that keeps a person within the framework of interactions with nature allowed by the laws;

- Esthetic culture, which creates conditions for emotional perception of beauty and harmony in nature;

- Physical culture, which directs a person to the effective development of his natural essential forces;

- Moral culture, which spiritualizes the relationship of a person to nature.

Ecological culture contributes to the preservation and development of the "naturesociety" system. Today, the time has come to synthesize social and natural principles in culture on the basis of a deep understanding of nature, the urgent need to form a human attitude of respect for nature as a prerequisite for its survival. Therefore, the most important indicator of the level of culture of modern society as a whole and man in particular is the awareness and implementation of environmental principles in the activities of people to preserve and reproduce natural resources.

Today, companies should pay special attention to the issues of environmental responsibility, analyze and optimize their environmental footprint. It is important that the environmental policy is approved and supported by the top management. The Company's management should recognize its leading role in making environmentally responsible decisions and conduct targeted work with the personnel, shaping their environmental thinking and behavior (environmental culture). We also make effective use of modern technologies to preserve the environment and conduct an open dialogue with the authorities, local NGOs and other communities in the area where we operate regarding the state of the environment. The company, which supports environmental responsibility, traditionally develops an environmental policy aimed at introducing environmental principles into all activities of the company.

Let's consider the measures that should be used by Russian companies in their environmental policy to form an environmental culture of personnel.

\subsection{Support and participation in the "Green Office" project}

Environmentally responsible companies began to actively support programs within the framework of the "Green Office" project (proposed by Greenpeace), which has existed in Russia since 2008. Its main goal is to attract public and business attention to environmental problems and show how everyone can help the environment without leaving the office of their company. Companies supporting the Green Office project think about the need to organize office space and take care of the environment and the health of their employees. This is achieved mainly by reducing the consumption of energy and resources for office maintenance, and thus reducing emissions of harmful substances into the atmosphere, 
which are the main cause of global climate change.

In order to create an environmental culture among our staff, we need to have a clear understanding of the goals and benefits of this project and the tools to achieve them. The authors have made a selection of such tools, based on the experience of using the "Green Office" project by advanced companies operating in Russia $[1,2,6]$. Objectives of the "Green Office" project and tools to achieve them are presented in Table 1.

Table 1. Objectives of the "Green Office" project and tools to achieve them

\begin{tabular}{|c|c|}
\hline Objectives & Tools \\
\hline $\begin{array}{l}\text { 1. Reduction of } \\
\text { greenhouse gas emis- } \\
\text { sions into the atmos- } \\
\text { phere: } \\
1.1 \text { Electricity and } \\
\text { heat savings }\end{array}$ & $\begin{array}{l}\text { - Energy-saving equipment is used, incandescent lamps are re- } \\
\text { placed by energy-saving lamps (for state-owned companies, this is } \\
\text { a requirement of the law, which defines target criteria for reducing } \\
\text { energy consumption); } \\
\text { - Control of lighting, air conditioning and ventilation systems, } \\
\text { equipment (if possible, natural daylighting is used, the lights are } \\
\text { switched off when the last person leaves the room, the supply of } \\
\text { warm/cooled air is reduced outside working hours, and it is rec- } \\
\text { ommended not to leave the equipment in standby mode); } \\
\text { - It is recommended that stairs are used whenever possible, not } \\
\text { elevators; } \\
\text { - Coffee machines with low energy consumption, are used, etc. }\end{array}$ \\
\hline $\begin{array}{l}1.2 \text { Fuel saving and } \\
\text { reduction of air pollution }\end{array}$ & $\begin{array}{l}\text { - Employees will roll back from frequent business trips, and } \\
\text { modern telecommunication technologies make it possible to re- } \\
\text { place them at video conferences and conference-calls; } \\
\text { - Environmentally friendly vehicles are selected when planning } \\
\text { trips: hybrid cars, electric cars, bicycles; } \\
\text { - Drivers are recommended to build optimal routes for vehicle } \\
\text { operation, etc. }\end{array}$ \\
\hline $\begin{array}{l}\text { 2. Reduction of water } \\
\text { consumption and pollu- } \\
\text { tion }\end{array}$ & $\begin{array}{l}\text { - Timely shutdown of taps by employees; } \\
\text { - Use of electronic or mechanical metered water supply sys- } \\
\text { tems; } \\
\text { - Use of environmentally friendly household chemicals; } \\
\text { - It is recommended not to allow solid objects, hazardous chem- } \\
\text { icals, oils, medicines, oil products, etc. to enter the sewerage sys- } \\
\text { tem. }\end{array}$ \\
\hline $\begin{array}{l}\text { 3. Reducing the nega- } \\
\text { tive impact of waste on } \\
\text { the environment and } \\
\text { human health: } \\
\quad 3.1 \text { Reduction of } \\
\text { waste generation }\end{array}$ & $\begin{array}{l}\text { - It is recommended not to print the document, but to read it } \\
\text { from the screen of the electronic device; } \\
\text { - Printing out rough material on the back of the used sheet of } \\
\text { paper and using the "double-sided printing" function; } \\
\text { - Electronic document management is introduced, which reduc- } \\
\text { es the amount of paper used by dozens of times, etc. } \\
\text { - Electronic subscription are used and, if possible, refuse to sub- } \\
\text { scribe to unclaimed journals and other printed materials; } \\
\text { - Minimum use of plastic tableware or complete rejection of } \\
\text { plastic in the offices of the company (you can give each employee } \\
\text { a special souvenir cup with the company logo and personal ini- } \\
\text { tials), etc. }\end{array}$ \\
\hline 3.2 Recycling & $\begin{array}{l}\text { - Office supplies (folders, envelopes, files), various containers } \\
\text { and things are reused; }\end{array}$ \\
\hline
\end{tabular}




\begin{tabular}{|c|c|}
\hline & $\begin{array}{l}\text { - Accumulator batteries are used instead of disposable batteries; } \\
\text { - Recycled slag can be used to cover the company's road sur- } \\
\text { face; } \\
\text { - Company offices are equipped with furniture suitable for re- } \\
\text { cycling, etc. }\end{array}$ \\
\hline 3.3 Sorting of waste & $\begin{array}{c}\text { - Paper bins appear specifically for paper, which allow for bet- } \\
\text { ter organization of its further recycling; } \\
\text { - Household (organic) and industrial waste will be stored sepa- } \\
\text { rately in specially allocated places, etc. }\end{array}$ \\
\hline $\begin{array}{l}\text { 3.4 Send the waste for } \\
\text { recycling and take it to a } \\
\text { collection point for dis- } \\
\text { posal }\end{array}$ & $\begin{array}{c}\text { - Glass bottles and cans, steel cans, plastic bottles, electronic } \\
\text { equipment and devices, batteries, light bulbs are sent for recycling; } \\
\text { - Collection of waste paper (unwanted newspapers, magazines, } \\
\text { postal mail, cardboard), etc. }\end{array}$ \\
\hline $\begin{array}{l}\text { pollution (and improve- } \\
\text { ment of employees' } \\
\text { health) }\end{array}$ & $\begin{array}{c}\text { - Specially designated smoking areas are organized in the com- } \\
\text { pany's offices (a ban on smoking is introduced); } \\
\text { - Greenery is organized in places where employees work; } \\
\text { - Employees use alternative means of transportation: public } \\
\text { transport, bicycle or walking, etc. }\end{array}$ \\
\hline
\end{tabular}

The "Green Office" project allows saving money on maintenance of office premises and economical attitude to the used resources, and to be more competitive in the market.

\subsection{Participation of the company in actions organized by various environ- mental organizations}

It is important for companies to carry out environmental programs both with local nonprofit organizations, which have a better understanding of the problems of the region, and with organizations working throughout the country (world), which have a broader vision of environmental issues. They usually interact and complement each other.

The experience of Nestlé in Russia, which produces food and beverages, is an expert in the field of proper nutrition and healthy lifestyle. Employees of the company, together with the local NGO "Waste.Bolshe.net", have been taking part in the ecological action "Operation Clean Coast" for several years now: they take away waste on the banks of Moscow and Moscow region water reservoirs. For several years now, Nestlé has been supplying food to polar expeditions to the North Pole conducted by the Arctic Institute. The purpose of these expeditions is to determine the state of ice cover in the Arctic and all climatic processes in this vast and poorly studied region.

WWF is the organizer of mass actions in the world, one of the largest independent international conservation organizations, working in more than 100 countries. For example, employees of the Russian telecommunications company «VimpelCom» joined WWF's Earth Hour campaign. Employees of the company turned off external and internal lighting for one hour in more than 30 administrative offices across the country, and in a number of cities the lighting of advertising structures was switched off $[7,14]$. Switching off the lights is symbolic and not intended to save electricity. "Earth Hour" is the most massive ecologi- 
cal action on the planet, attracting attention to careful and responsible attitude to the nature and resources of the planet. Employees of «VimpelCom» also supported the "Car Free Day" campaign. It is an annual WWF event held around the world under the motto "In a city without my car", a symbolic event designed to remind people of the negative impact of cars on the environment and human health (more than $90 \%$ of atmospheric pollution is caused by motor vehicles), and to encourage people to use alternative means of transportation: public transport, bicycles or walking. Good practices of such use have been actively practiced in many cities around the world (Amsterdam, Copenhagen, Stockholm, Helsinki, Toronto, Bogota and others).

For Russia, this experience has not yet become widespread, but some companies are thinking about alternatives, the use of individual cars for travel to work, organizing free transportation of employees to work on large buses. The experience of «TNT Express» is interesting. The company has created the "Green Driving Clean" (DrivingClean) program to reduce carbon dioxide emissions into the atmosphere, using alternative delivery methods. Firstly, the company's fleet was equipped with hybrid or electric vehicles; secondly, the company arranged for bicycle delivery of documents and small-size cargo weighing up to 5 $\mathrm{kg}$ inside the city of Ekaterinburg. The main goal of such programs is not only to make the company's business environmentally friendly, but also to encourage its employees to make individual efforts to reduce $\mathrm{CO} 2$ emissions when travelling to work and for personal use $[2]$.

\subsection{Creation of the company's own volunteer environmental organization}

Employees of the companies have the opportunity to join various social movements or projects, and can do so on the initiative of in-house environmental volunteering. The company may establish its own environmental volunteer organization, as for example, in the KPMG network of audit companies - «Green Championship League». It initiates a variety of activities among the network's member firms' employees, from planting trees and cleaning up territories to implementing the Global Green Initiative, an international environmental protection program aimed at combating the causes and consequences of climate change. The organization acts as a sponsor and partner in the implementation of all-Russian environmental actions. They are interested in involving more employees of their companies in environmental volunteering. Employees who are already involved in environmental volunteering conduct thematic workshops for "uninvolved" personnel. They not only inform about the environmental way of life, but also demonstrate by their example the use of these practices in everyday life and work.

\subsection{Organization of environmental charity events}

By participating in such charitable activities, employees and their family members, their friends can give their unnecessary things (clothes, books, household utensils, etc.) to people who need these things. Thus, they will support one of the basic principles of ecology - reuse. If the majority of consumers do so, then producers will have to review their environmentally irresponsible policies, because most products are designed for a short life, so that the buyer will soon come for new purchases.

\subsection{Development and use of innovative "green" technologies by companies}

In the company, which are thinking about environmentally friendly business, their own 
engineers and designers, as well as third parties, constantly come up with the latest energysaving technologies that have a positive impact on the environment.

In 2004, company "VimpelCom" implemented a unique project for Russia and European countries on the use of solar energy to operate base stations in hard-to-reach places where there was no grid power supply. Experience in operating such systems has confirmed their high efficiency, reliability and environmental friendliness. Another solution that has a positive impact on the environment is the use of flywheels in the new Data Center in Yaroslavl, which requires virtually no energy for continuous rotation of diesel generators. Thus, the company has minimized the problem of traditional Data Centers - the disposal of a large number of harmful batteries, which are used to start diesel generators in the event of a power outage [2].

\subsection{Creation of resource-saving products by the company}

Today, companies are thinking more seriously about the creation of products that meet the characteristics of resource conservation and reduce the environmental footprint on the environment and human health. For example, "BSH Household Appliances" (a subsidiary of the BSH Group in Russia), which produces household appliances, pays much attention to the parameter of environmental friendliness during operation. The company's engineers are constantly searching for new ideas to create technologies that not only increase the productivity of household appliances, but also reduce their consumption of water and electricity. The company has developed a method of systematic environmental impact assessment of products.

\subsection{Establishing a dialogue and interaction with the local community}

The formation of a positive external environmental image of the company fully depends on direct communication between the company and the public. The more ecologists of the enterprise will directly tell the public about the enterprise (speeches at schools, colleges, universities, and other enterprises), its problems, ways of solving them, and future prospects, the more friendly its attitude to the enterprise will be. The organization of excursions around the enterprise ("Open Days") will help to keep the image of a positive enterprise that cares about the environment and working people for a long time.

\subsection{Conducting informational and educational activities among the compa- ny's employees}

Eco-lectures should be organized inside the company to inform and educate employees on how to live sustainably. There, employees will be able to learn that many of their daily decisions (shopping, eating, transportation, etc.) shape the future of our planet. Every employee should be aware of and make a personal contribution to a sustainable future by demonstrating environmental behaviour every day, both at work (e.g. the Green Office project) and at home (turning off water taps when brushing teeth, and turning off plastic 
bags and replacing them with reusable eco-pouches). This can be facilitated by familiarization with the international environmental movement "Zero waste", the main idea of which is to minimize waste, which helps to significantly reduce the negative impact on the environment.

In addition, with the growth of environmental education, the attention of the Russian population as clients to the environmental performance of enterprises will grow. And it is important for the management of the companies to popularize the practices of domestic and foreign companies in the field of environmental and social responsibility, highlighting the most advanced of them.

Company employees should be informed and involved in various city eco-events. An example of this is the "Do It Yourself" project, which has been held annually in Russian cities since 2011. This project unites people and initiative groups that make specific positive changes in their cities and unite residents for such actions. The participants of the project disseminate information on nature conservation, conscious consumption, healthy lifestyle, recycling and recycling points. They organize events on garbage removal, tree planting and waste paper collection, in support of cycling and alternative modes of transport.

For the company's employees, participation in environmental events becomes a real opportunity to be not just outside observers, but also to try to change the world for the better. Employees' awareness of personal environmental responsibility and its use in their daily work is an important aspect of corporate culture and one of the elements of formation and expression of their civic position. Such a new way of life - the ecological way of life - helps to unite the company's employees better. Companies should also reflect on changes in their marketing activities, presenting corporate environmental responsibility as one of the brand values.

The company's staff should be fully aware of the extent of the company's impact on the environment and understand their role in this impact (how they affect the environment and what they should do to reduce this impact). This can be done with the help of environmental screens. Also, the screen should contain information about the impact of the organization on the environment, the measures taken to reduce the impact, and the participation of employees in environmental activities. It should include a comparative analysis of the implementation of these measures ("as it was" and "as it became"), preferably with photographs illustrating these changes. It is necessary that after the implementation of the event, the management should express its gratitude to the employees at the general meeting. It is important for them to see that the management is concerned about the environment, that the organisation is changing for the better and that they themselves are actively involved in this process. Employees should be aware of the value of environmental protection for the company.

In this way, by shaping the environmental thinking and behaviour of the staff, the company will be able to achieve a noticeable reduction in the environmental impact, while at the same time improving the internal and external image of the organization.

\section{Discussion}

Today, the most important indicator of the level of culture of modern society in general and the individual in particular is the awareness and implementation of environmental principles in their activities for the preservation and reproduction of natural resources. The development of environmental culture among the company's personnel proves that it is important that employees not only possess the necessary knowledge, but also use it in everyday life and work. The presence of an environmental culture in people contributes to the preserva- 
tion and development of the system of "nature - society", the formation of a respectful attitude to nature as a prerequisite for their survival, awareness of the priority of global environmental interests, and at the same time, the personal responsibility of each person on Earth.

\section{Conclusion}

As a result of this research, the basic concepts directly related to the environmental management of personnel were considered, namely, environmental thinking, environmental behavior, environmental culture, and the relationship between these concepts. A list of measures to be used by Russian companies in their environmental policy to form an environmental culture of personnel is formulated. The advantages of creating an environmental culture of personnel are described, and tools have been developed to help companies operating in Russia to achieve their environmental goals based on the experience of using the "Green Office" project.

As a result of the study, the management of Russian companies formulated a priority in environmentally responsible behavior, in the formation of an ecological culture among their staff, which will reduce the negative impact of the organization on the environment, contribute to its sustainable development, business competitiveness and the formation of a positive internal and external image.

\section{References}

1. How to make the Green Office, V Russian conference, Greenpeace. (2013)

2. Environmental Responsibility of Business: Experience and Prospects, Business and Society (2011)

3. N. N. Shlyago, GreenControlling: Proceedings of the III International Congress on Controlling, p. 303-318 (St. Petersburg, 2013)

4. O. Rostova, S. Shirokova, A. Shmeleva, MATEC Web Conf. 170, 01024 (2018) DOI: https://doi.org/10.1051/matecconf/201817001024

5. Atlas of new professions, (Moscow School of Management SKOLKOVO, 2014).

6. Russian Standart, Rosneft: Company's Ecological Responsibility (2017).

7. M. N. Mukhanova, Soc. J., 2, 23, 74-95 (2017) DOI: 10.19181/socjour.2017.23.2.5161

8. I. N. Aleksandrov, M. Yu. Fedorova, Sc. J. of KubSAU, 10, (2017) DOI: 10.21515/1990-4665-134-063

9. A. Tatarkin Econ. \& Soc. Ch.: facts, trends, forecast, 24, 42-59, (2012)

10. N. F. Tsertsek, Issues of environmental education, 3, 35-37, (2008)

11. A. R. Bril, O. V. Kalinina, I. V. Ilin, 2017 Proc. of the 29th IBIMA Vision 2020: Inn. Man., 2268 - 2278 (2017) 